\title{
Economic and organizational sustainability of a negative-pressure portable device for the prevention of surgical-site complications
}

This article was published in the following Dove Press journal:

ClinicoEconomics and Outcomes Research

12 June 2017

Number of times this article has been viewed

\section{Emanuela Foglia' \\ Lucrezia Ferrario' \\ Elisabetta Garagiola' \\ Giuseppe Signoriello² \\ Gianluca Pellino 3 \\ Davide Croce ${ }^{1,4}$ \\ Silvestro Canonico 3}

'Centre for Health Economics, Social and Health Care Management LIUC University, Castellanza, Italy; ${ }^{2}$ Department of Mental Health and Preventive Medicine, University of Campania "Luigi Vanvitelli”, Naples, Italy; ${ }^{3}$ School of Medicine, University of Campania "Luigi Vanvitelli”, Naples, Italy; ${ }^{4}$ School of Public Health, Faculty of Health Sciences, University of the Witwatersrand, Johannesburg, South Africa
Correspondence: Lucrezia Ferrario Centre for Health Economics, Social and Health Care Management - LIUC University, Corso Matteotti, 22, 21053

Castellanza, VA, Italy

Tel +39 33I 572504

Fax +39331572513

Email lferrario@liuc.it
Purpose: Surgical-site complications (SSCs) affect patients' clinical pathway, prolonging their hospitalization and incrementing their management costs. The present study aimed to assess the economic and organizational implications of a portable device for negative-pressure wound therapy (NPWT) implementation, compared with the administration of pharmacological therapies alone for preventing surgical complications in patients undergoing general, cardiac, obstetrical-gynecological, or orthopedic surgical procedures.

Patients and methods: A total of 8,566 hospital procedures, related to the year 2015 from one hospital, were evaluated considering infection risk index, occurrence rates of SSCs, drug therapies, and surgical, diagnostic, and specialist procedures and hematological exams. Activitybased costing and budget impact analyses were implemented for the economic assessment.

Results: Patients developing an SSC absorbed i) $64.27 \%$ more economic resources considering the length of stay ( $€ 8,269 \pm 2,096$ versus $€ 5,034 \pm 2,901, p<0.05$ ) and ii) $42.43 \%$ more economic resources related to hematological and diagnostic procedures ( $€ 639 \pm 117$ versus $€ 449 \pm 72, p<0.05$ ). If the innovative device had been used over the 12 -month time period, it would have decreased the risk of developing SSCs; the hospital would have realized an average reduction in health care expenditure equal to $-0.69 \%$ ( $-€ 483,787.92)$ and an organizational saving in terms of length of stay equal to $-1.10 \%$ ( -898 days), thus allowing 95 additional procedures.

Conclusion: The implementation of a portable device for NPWT would represent an effective and sustainable strategy for reducing the management costs of patients. Economic and organizational savings could be reinvested, thus i) treating a wider population and ii) reducing waiting lists, with a higher effectiveness in terms of a decrease in complications.

Keywords: NPWT portable device, budget impact analysis, economic analysis, organizational advantage, Italy

\section{Introduction}

A surgical-site complication (SSC) is defined by the Centers for Disease Control and Prevention (CDC) as "any infection occurring within 30 days post-operatively that can be attributed to surgery, and within one year of placing an implant". ${ }^{1}$ SSCs represent a majority of postoperative complications, reaching a prevalence rate of $38 \%$ in surgery departments worldwide. ${ }^{2}$ In the Italian setting, national evidence declares that the incidence of SSCs is equal to $5.2 \%$ in every 100 surgical procedures, thus being comparable with European studies. ${ }^{3}$

The development of SSCs affects the management costs of patients, prolonging their hospitalization, with an average increase across specialties of 6.5 days $;{ }^{4-6}$ therefore, this 
condition should be an urgent priority for hospital managers from a social and an economic point of view.

Since wounds have a considerable impact on patient morbidity (29\% risk of ICU admission for at least 1 day $^{6}$ ), mortality (responsible for up to $30 \%$ of deaths occurring within 30 days of surgery ${ }^{7}$ ), daily functioning, and quality of life, ${ }^{8,9}$ they require high-quality and systemic treatment, as well as adequate preventive activities devoted to the reduction of their occurrence rate. In real-life practice, the occurrence rates of SSCs are influenced by several patientrelated factors, such as i) age, ii) high-dose intake of steroid drugs, iii) alcohol abuse, iv) smoking habits, v) high body mass index (BMI), and vi) concomitant conditions. ${ }^{10,12}$ In this view, patients presenting at least one of the above-mentioned risk factors require a proper clinical management within the surgical department, with regard to the administration of an optimal SSC prevention strategy.

According to this, the standard of care proposed by scientific guidelines is the administration of appropriate and timely antimicrobial prophylaxis before incision, depending on the type and severity of the surgical procedure. ${ }^{13}$

Although different prophylaxis strategies have been shown to reduce the incidence of SSCs, many patients presenting the above-mentioned risk factors have required other/additional prevention approaches. Literature reports that negative-pressure wound therapy (NPWT) may be considered as a valid option for reducing the incidence of SSCs, which will lead to an improvement in the results of the wound treatment. ${ }^{14-20}$ NPWT is a therapeutic technique that uses a vacuum dressing to promote healing of acute or chronic wounds, and enhances the healing of second- and third-degree burns by applying subatmospheric pressure to the local wound environment, ${ }^{21,22}$ using a sealed wound dressing connected to a vacuum pump. ${ }^{23}$ The implementation of NPWT is indicated for the treatment of postoperative and dehisced surgical wounds, pressure ulcers, diabetic/ neuropathic ulcers, traumatic wounds, skin flaps and grafts, venous insufficiency ulcers, and explored fistula. ${ }^{24}$

The adoption of traditional NPWT has been associated with an average reduction in the occurrence rate of SSC from $46 \%$ to $50 \%$, or even higher in some specific surgical settings. ${ }^{25,26}$

In recent years, an innovative portable device for NPWT was designed, consisting of a 7-day battery-powered negativepressure therapy device and an easy-to-place dressing. ${ }^{26}$

Although the effectiveness of the portable device has been amply reported in literature, ${ }^{12,18,27,28}$ and is shown to be more effective compared with traditional NPWT, little is known with regard to the economic impact of its introduction and consequent adoption into clinical practice.

Focusing on the Italian setting, characterized by spending review actions, an in-depth analysis of economic resources is therefore required for the proper and adequate assessment and introduction of alternative treatments for patients developing SSCs.

Moving on from these premises, the general objective of the present study was to determine whether there is an economic or organizational advantage for a hospital that decides to introduce the innovative NPWT portable device into clinical practice in accordance with a multidimensional approach. The primary objective of the study was to estimate the budget impact of the introduction of the innovative technology (in addition to the antibiotic prophylaxis), compared with the historical situation based on the administration of pharmacological therapies alone for the prevention of SSCs in patients undergoing general, cardiac, obstetricalgynecological (ob-gyn), or orthopedic surgical procedures. For the definition of the budget impact analysis (BIA), the management costs for a single patient, who does or does not develop an SSC, were investigated in order to understand the absorption of differential economic resources (additional expenditure or economic savings). The secondary objective of the study was to define the potential organizational benefits related to the introduction of the innovative technology into the clinical activities, in terms of reduction in length of stay, thus allowing for a higher level of accessibility to the health care services and covering the needs of an incremental group of citizens.

\section{Methods}

This study was conducted from January to April 2016, and involved the hospital "Azienda Ospedaliera Universitaria Seconda Università di Napoli” (Naples, Italy), the real-life data of which were retrospectively collected, with reference to surgical activities performed in 2015. In accordance with the aims of the study, patients undergoing general, cardiac, ob-gyn, or orthopedic surgical procedures entered the model. In this view, 8,566 administrative records represented the population under assessment, for whom the following input variables were collected: the infection risk index (IRI), SSC rates, BMI, and the American Society of Anesthesiologists (ASA) scores. Once the population had been defined, two groups of patients were considered: i) patients who had developed an SSC, and ii) patients who had not developed an SSC.

A formal approval was received by the Hospital General Directorate of the "Azienda Ospedaliera Universitaria 
Seconda Università di Napoli”, Naples, Italy. It is important to specify that the patients' consent to review their medical records was not required since economic data were collected from administrative databases derived from hospital administrative flows, and the patients were already anonymized. Furthermore, information concerning the infection occurrence rate was already collected by the hospital and regional health authorities.

A study design, composed of the following logical phases, was developed which considered two dimensions of the acknowledged EUnetHTA Core model: ${ }^{29}$ i) the economic dimension (leading to the identification, quantification, and evaluation of resources required for a single clinical process, with the evaluation of all the direct costs, with a consequent estimation of the hospital budget impact), and ii) the organizational dimension (leading to the quantification of the possible impacts of the innovative technology on the hospital processes).

\section{Economic evaluation of the clinical pathway}

In accordance with the activity-based costing analysis implementation, aimed at calculating and measuring the costs and performances of activities, resources, and cost objects, ${ }^{30}$ the economic impact of each patient was determined using the following components, estimating the costs arising from the use of resources in hospital: i) general cost of the procedures, ii) length of stay, iii) equipment, iv) wound dressings, v) nondrug therapy-related costs including diagnostic tests and specialist visits, vi) antibiotic therapies, and vii) NPWT portable device. In this view, only direct costs were considered, comprising all costs for providing care, such as physician and nursing staff salaries and expenditures on medications and other medical supplies. ${ }^{31}$

All the above-mentioned health care expenditure items were distinguished based on whether or not there was development of an SSC.

The economic analysis, assuming the hospital point of view, took into consideration the hospital health care costs and the drug costs derived from the officially published National Health Service price list, referring to 2015 values.

\section{Budget impact model and scenario analysis}

A BIA was conducted considering the hospital perspective over a 12-month time horizon, in order to give a prediction with regard to the economic and financial consequences referring to the adoption and diffusion of new technologies into a health care system with finite resources. ${ }^{32}$ Since the analysis covered a 12-month time horizon, the model had a static nature, thus not requiring any patient to exit the model due to death or other complications.

For the implementation of a proper budget impact model, two comparative scenarios were investigated (baseline versus innovative), thus being different for the use of the alternative technologies in the prevention of SSCs. In this view, the market shares of the technologies under investigation were identified considering real-life activities of the hospital involved in the study.

With regard to the baseline scenario, the antibiotic therapy was administered to all the eligible patients, being consistent with regional data ${ }^{33}$ that reported that the administration of antibiotic prophylaxis depends on the severity of the surgical procedure, thus demonstrating that not all surgical patients present a high infection risk requiring a specific prevention strategy. With regard to the innovative scenario, the new portable device was implemented for all eligible patients, as a support to the traditional antibiotic prophylaxis, considering patients who were more likely to develop SSCs, according to the hospital policies. These treatment protocols declared that the portable devices could be administered to patients presenting an ASA score higher than 2 or an IRI higher than 3. It should be noted that the portable device efficacy was derived from the most recent and updated literature evidence available. ${ }^{12,18,27,28}$

Once the model had been structured, two one-way scenario analyses were performed, in order to ensure the robustness of the BIA results. The SSC occurrence was changed, within the different settings under assessment, on the basis of data derived from the hospital involved, and the distribution of the population among the different preventive strategies was modified.

Results were expressed in terms of ceasing or emerging costs deriving from the introduction of the innovative technology.

\section{Organizational impact}

The organizational advantages related to the introduction of the innovative technology, in comparison with the baseline scenario, were examined. In particular, the average number of days a patient spent in hospital after the surgical procedure was the variable investigated, thus making a distinction between SSC patients and "non-SSC" patients. In this view, each patient's clinical pathway was evaluated, considering the same scenarios proposed for the BIA, using "days spent in hospital after the surgical procedure" instead of the "economic clinical pathway of a patient having undergone 
the surgical procedure". Results were expressed in terms of ceasing or emerging hospital days deriving from the introduction of the innovative technology. The potential decrease in the length of hospitalization was also evaluated, in order to define the possibility for the hospital of reference to perform additional surgical procedures, thus reducing the surgical waiting lists and optimizing the patient's clinical pathway. Another variable under investigation was the number of procedures produced in the case of SSC reduction, during the 12 months under assessment.

\section{Results}

\section{Results from the study sample}

During the year 2015, 8,566 patients underwent surgical procedures: $30 \%(\mathrm{~N}=2,576)$ general surgery, $50 \%(\mathrm{~N}=4,283)$ ob-gyn, 4\% ( $\mathrm{N}=381)$ orthopedic surgery, 6\% ( $\mathrm{N}=521)$ cardiac surgery, and the remaining $10 \%(\mathrm{~N}=814)$ other procedures.

Most of the sample was composed of males (61.58\%). Individuals were 52.83 \pm 3.89 years old (range: $30-74)$ : in particular, women were younger than men, even if no statistical significance was found (44.80 \pm 4.41 versus $58.57 \pm 5.04$, $p>0.05)$.

The occurrence rate of SSCs differed on the basis of the surgical setting under investigation: patients undergoing orthopedic surgery presented a higher risk of developing an SSC (average value: 6.37\%; range: 1.14\%-8.49\%), followed by other surgical procedures (average value: $3.18 \%$; range: $2.36 \%-4.02 \%$ ), general surgery (average value: $2.97 \%$; range: $1.36 \%-4.62 \%$ ), cardiac surgery (average value: $2.76 \%$; range: $2.18 \%-4.14 \%$ ), and ob-gyn surgery (average value: $1.75 \%$; range: $0.43 \%-4.38 \%$ ).

Focusing on the BIA scenarios, with regard to the historical situation, the antibiotic therapy was administered to $90.95 \%$ of patients, whereas the no-prevention strategy was attributed to $9.05 \%$. With regard to the innovative scenario, according to the previously mentioned inclusion criteria (ASA higher than 2 and IRI higher than 3), the following proportion of population resulted potentially eligible for the NPWT portable device: from $5.64 \%$ to $6.21 \%$ in general surgery, from $4.04 \%$ to $4.44 \%$ in ob-gyn, from $4.63 \%$ to $5.09 \%$ in orthopedic procedures, from $10.30 \%$ to $11.33 \%$ in cardiac surgery, and from $6.15 \%$ to $6.77 \%$ considering all the other surgical procedures.

Detailed information concerning the population entering the model, within the two different scenarios, is reported in Table 1.

\section{Results from the activity-based costing analysis: economic input of the model}

Results showed that the cost related to both the surgical procedures and the prevention strategies did not differ in the case of SSC development: since the complication occurred after the surgical procedure, differences between groups were observed, and measured in the following phases.

In addition, the only difference between the baseline and the innovative scenarios was related to the purchasing cost of the innovative device, around $€ 145.00$ plus $€ 1.60$, with

Table I Population distribution in the investigated scenarios

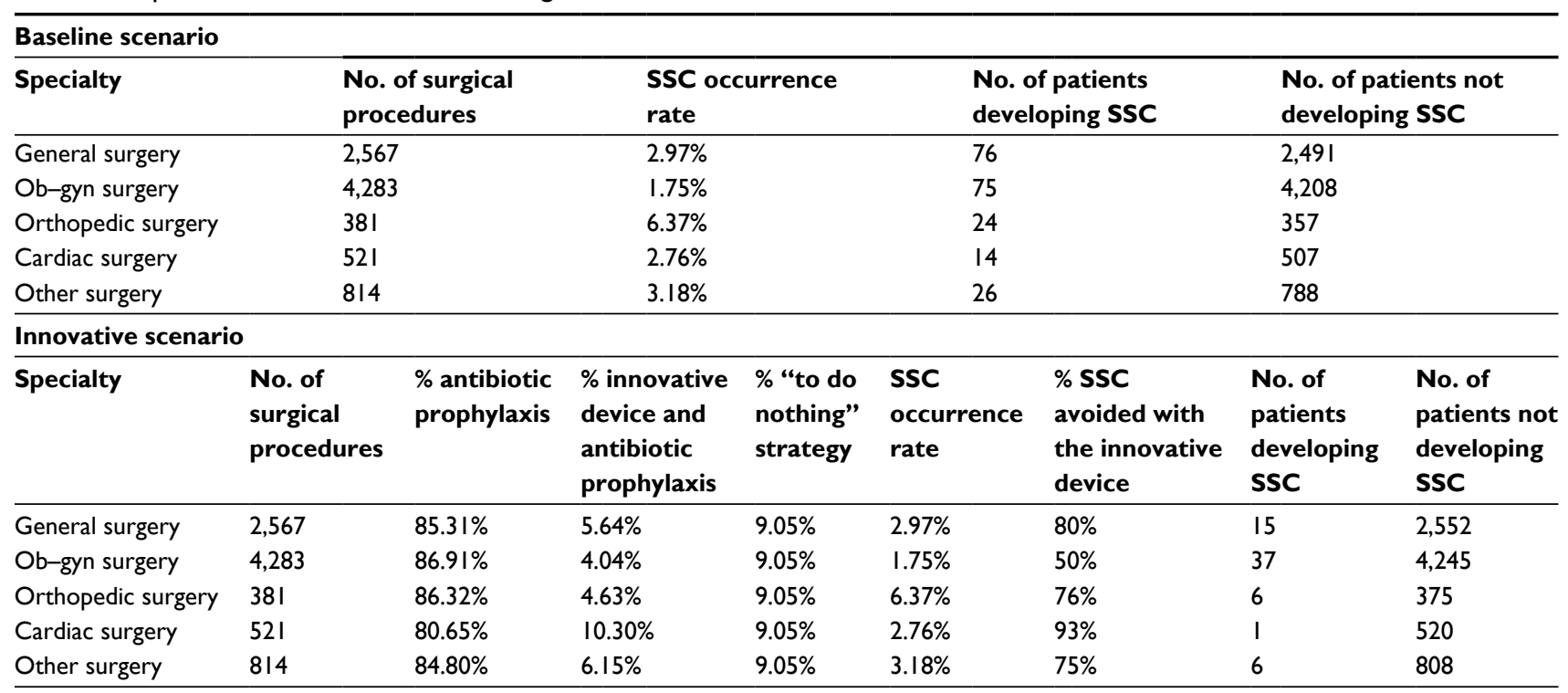

Abbreviations: SSC, surgical-site complication; ob-gyn, obstetrical-gynecological. 
regard to the human resources devoted to its implementation, and the type of wound dressing used.

On average, each patient who underwent a surgical procedure spent $11.69 \pm 3.04$ days in hospital, thus requiring $€ 6,278.77 \pm 1,631.96$ for medical management and $€$ $522.42 \pm 65.85$ for the additional hematological and diagnostic investigations.

Table 2 shows the economic value related to the management of a surgical patient, stratified by presence or absence of an SSC. It emerged that the occurrence of an SSC led to a more significant amount of economic resources absorbed for the management of a patient. Health care costs increased substantially for a patient with an SSC, absorbing i) $64.27 \%$ more economic resources, considering the length of stay (€ 8,269 $\pm 2,096$ versus $€ 5,034 \pm 2,901, p<0.05$ ), and ii) $42.43 \%$ more economic resources related to hematological and diagnostic procedures $(€ 639 \pm 117$ versus $€ 449 \pm 72$, $p<0.05)$.

\section{$\mathrm{BIA}$ and scenario analysis}

From the comparison of the above-mentioned scenarios, it emerged that a hospital would achieve an average reduction in health care expenditure equal to $-0.69 \%$ ( $-€ 483,787.92)$, with respect to the baseline scenario. This economic saving was strictly related to the lower number of days that a patient spends in hospital, and the lower number of tests and diagnostic procedures performed.
All results deriving from the scenario analysis showed the robustness of the proposed innovative device even with a decrease in the efficacy rates of all the treatments, thus resulting in a lower number of patients developing an SSC: the introduction of the portable device for negative wound pressure would result in a hospital achieving an economic saving.

In this view, Table 3 reports that the health care expenditure devoted to the management of surgical patients would decrease, ranging from a minimum of $-0.27 \%$ (€ $189,414.95)$ to a maximum of $-1.22 \%$ ( $-€ 860,631.51)$, depending on the occurrence rate of SSCs.

Table 4 shows that, even with a different population's distribution among the preventive strategy, a hospital could benefit from an economic advantage equal to $-0.69 \%$. In particular, the saving varied from $-€ 479,552.79$ to $-€$ $479,871.78$, on the basis of the different preventive strategy assumed.

\section{Organizational impact}

The average length of stay in hospital was equal to $9.40 \pm 3.53$ days for a patient who did not develop any SSC and $15.40 \pm 5.63$ days for a patient who developed an SSC, thus resulting in a difference of 6 days, consistent with literature data. $^{4,5}$

In this view, considering the number of complications that occurred in 2015 , the innovative device had a positive impact

Table 2 Health care expenditure items

\begin{tabular}{|c|c|c|c|c|}
\hline Health care expenditure items & Costs & & & \\
\hline General surgical procedure & $€ 3,652.21$ & & & \\
\hline Ob-gyn surgical procedure & $€ 1,089.64$ & & & \\
\hline Orthopedic surgical procedure & $€ 3,448.67$ & & & \\
\hline Cardiac surgical procedure & $€ 6,4 \mid 8.31$ & & & \\
\hline Other surgical procedure & $€ 3,652.21$ & & & \\
\hline Antibiotic therapy (general surgery) & $€ 6.38$ & & & \\
\hline Antibiotic therapy (ob-gyn surgery) & $€ 5.82$ & & & \\
\hline Antibiotic therapy (orthopedic surgery) & $€ 6.90$ & & & \\
\hline Antibiotic therapy (cardiac surgery) & $€ 13.59$ & & & \\
\hline Antibiotic therapy (other surgery) & $€ 8.17$ & & & \\
\hline Health care expenditure items & $\begin{array}{l}\text { No SSC } \\
\text { development }\end{array}$ & $\begin{array}{l}\text { SSC } \\
\text { development }\end{array}$ & Difference & Difference \% \\
\hline Length of stay & $€ 5,034.38$ & $€ 8,269.80$ & $€ 3,235.42$ & $64.27 \%$ \\
\hline Laboratory exams and diagnostic procedures & $€ 449.43$ & $€ 639.22$ & $€ 189.79$ & $42.23 \%$ \\
\hline Wound dressing (general surgery) & $€ 46.53$ & $€ 47.98$ & $€ 1.45$ & $3.12 \%$ \\
\hline Wound dressing (ob-gyn surgery) & $€ 46.53$ & $€ 47.98$ & $€ 1.45$ & $3.12 \%$ \\
\hline Wound dressing (orthopedic surgery) & $€ 94.00$ & $€ 125.00$ & $€ 31.00$ & $32.98 \%$ \\
\hline Wound dressing (cardiac surgery) & $€ 94.00$ & $€ 125.00$ & $€ 31.00$ & $32.98 \%$ \\
\hline Wound dressing (other surgery) & $€ 70.27$ & $€ 86.49$ & $€ 16.22$ & $23.08 \%$ \\
\hline
\end{tabular}

Abbreviation: ob-gyn, obstetrical-gynecological; SSC, surgical-site complication. 


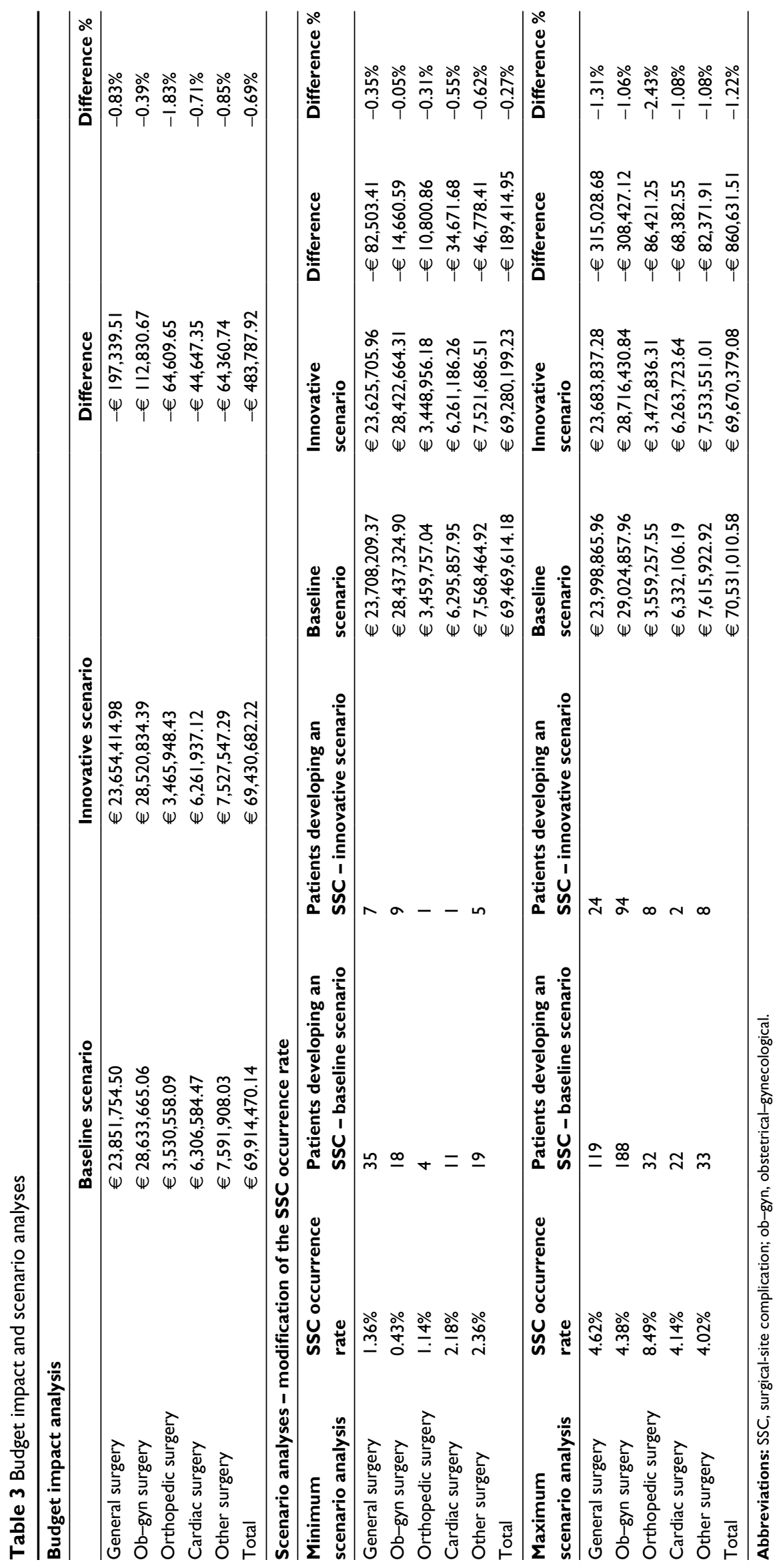


Table 4 Scenario analyses

\begin{tabular}{|c|c|c|c|c|c|c|c|}
\hline \multicolumn{8}{|c|}{ Scenario analyses - modification of the population distribution among the different prevention strategies } \\
\hline $\begin{array}{l}\text { Minimum scenario } \\
\text { analysis }\end{array}$ & $\begin{array}{l}\% \text { antibiotic } \\
\text { prophylaxis } \\
\text { in the } \\
\text { innovative } \\
\text { scenario }\end{array}$ & $\begin{array}{l}\% \text { innovative device } \\
\text { and antibiotic } \\
\text { prophylaxis in } \\
\text { the innovative } \\
\text { scenario }\end{array}$ & $\begin{array}{l}\text { \% "to do } \\
\text { nothing" } \\
\text { strategy in } \\
\text { the innovative } \\
\text { scenario }\end{array}$ & $\begin{array}{l}\text { Baseline } \\
\text { scenario }\end{array}$ & $\begin{array}{l}\text { Innovative } \\
\text { scenario }\end{array}$ & Difference & Difference \% \\
\hline General surgery & $84.74 \%$ & $6.21 \%$ & $9.05 \%$ & $€ 23,851,754.50$ & $€ 23,655,866.53$ & $-€ 195,887.96$ & $-0.82 \%$ \\
\hline Ob-gyn surgery & $86.51 \%$ & $4.44 \%$ & $9.05 \%$ & $€ 28,633,665.06$ & $€ 28,522,543.37$ & $-€ 111,121.69$ & $-0.39 \%$ \\
\hline Orthopedic surgery & $85.86 \%$ & $5.09 \%$ & $9.05 \%$ & $€ 3,530,558.09$ & $€ 3,466,041.32$ & $-€ 64,516.76$ & $-1.83 \%$ \\
\hline Cardiac surgery & $79.62 \%$ & $11.33 \%$ & $9.05 \%$ & $€ 6,306,584.47$ & $€ 6,262,218.57$ & $-€ 44,365.90$ & $-0.70 \%$ \\
\hline Other surgery & $84.18 \%$ & $6.77 \%$ & $9.05 \%$ & $€ 7,591,908.03$ & $€ 7,527,928.57$ & $-€ 63,979.46$ & $-0.84 \%$ \\
\hline Total & & & & $€ 69,914,470.14$ & $€ 69,434,598.36$ & $-€ 479,871.78$ & $-0.69 \%$ \\
\hline $\begin{array}{l}\text { Maximum scenario } \\
\text { analysis }\end{array}$ & $\begin{array}{l}\text { \% antibiotic } \\
\text { prophylaxis } \\
\text { in the } \\
\text { innovative } \\
\text { scenario } \\
\end{array}$ & $\begin{array}{l}\% \text { innovative device } \\
\text { and antibiotic } \\
\text { prophylaxis in } \\
\text { the innovative } \\
\text { scenario }\end{array}$ & $\begin{array}{l}\text { \% "to do } \\
\text { nothing" } \\
\text { strategy in } \\
\text { the innovative } \\
\text { scenario }\end{array}$ & $\begin{array}{l}\text { Baseline } \\
\text { Scenario }\end{array}$ & $\begin{array}{l}\text { Innovative } \\
\text { Scenario }\end{array}$ & Difference $€$ & Difference \% \\
\hline General surgery & $85.31 \%$ & $6.21 \%$ & $8.48 \%$ & $€ 23,851,754.50$ & $€ 23,655,959.88$ & $-€|95,794.6|$ & $-0.82 \%$ \\
\hline Ob-gyn surgery & $86.91 \%$ & $4.44 \%$ & $8.65 \%$ & $€ 28,633,665.06$ & $€ 28,522,643.06$ & $-€ 111,022.00$ & $-0.39 \%$ \\
\hline Orthopedic surgery & $86.32 \%$ & $5.09 \%$ & $8.59 \%$ & $€ 3,530,558.09$ & $€ 3,466,053.43$ & $-€ 64,504.66$ & $-1.83 \%$ \\
\hline Cardiac surgery & $80.65 \%$ & $11.33 \%$ & $8.02 \%$ & $€ 6,306,584.47$ & $€ 6,262,291.49$ & $-€ 44,292.98$ & $-0.70 \%$ \\
\hline Other surgery & $84.80 \%$ & $6.77 \%$ & $8.44 \%$ & $€ 7,591,908.03$ & $€ 7,527,969.49$ & $-€ 63,938.54$ & $-0.84 \%$ \\
\hline Total & & & & $€ 69,914,470.14$ & $€ 69,434,917.35$ & $-€ 479,552.79$ & $-0.69 \%$ \\
\hline
\end{tabular}

Abbreviation: ob-gyn, obstetrical-gynecological.

from an organizational perspective, with an optimization of the time spent in hospital after a surgical procedure, equal to an average value of $-1.10 \%$ ( -898 days) as presented in Table 5 .

Considering the case mix proposed in the study, related to the specific five typologies of surgical specialties, the decrease in the length of stay was converted into the number of additional and potential procedures a hospital could perform, in relation to the optimization of resources and reduction of complications (Table 6).

\section{Discussion and conclusion}

The results of the study, even starting from Italian and observational data, generate an interesting practical contribution, demonstrating the sustainability of prevention strategies for SSCs, being significantly replicable in other international settings. While the above-mentioned scenarios represent a simplification of the clinical pathways of surgical patients, the study could be considered as a relevant attempt to evaluate the worst-case scenario, thus equally achieving significant economic and organizational benefits. Considering all the cases and typology of surgical procedures, a higher level of variability in the surgical complications may lead to major economic savings in the different settings.
Table 5 Organizational impact: the decrease in the length of stay

\begin{tabular}{|c|c|c|c|c|}
\hline & $\begin{array}{l}\text { Baseline } \\
\text { scenario }\end{array}$ & $\begin{array}{l}\text { Innovative } \\
\text { scenario }\end{array}$ & Difference & $\begin{array}{l}\text { Difference } \\
\%\end{array}$ \\
\hline Seneral surgery & $24,587.72$ & $24,221.76$ & -365.96 & $-1.49 \%$ \\
\hline Ob-gyn surgery & $40,706.07$ & $40,481.23$ & -224.84 & $-0.55 \%$ \\
\hline Orthopedic surgery & $3,730.10$ & $3,619.34$ & -110.76 & $-2.97 \%$ \\
\hline Cardiac surgery & $4,982.98$ & $4,902.75$ & -80.23 & $-1.61 \%$ \\
\hline Other surgery & $7,807.99$ & $7,691.49$ & -116.50 & $-1.49 \%$ \\
\hline Total & $81,814.86$ & $80,916.57$ & -898.28 & $-1.10 \%$ \\
\hline $\begin{array}{l}\text { Minimum } \\
\text { scenario analysis }\end{array}$ & $\begin{array}{l}\text { Baseline } \\
\text { scenario }\end{array}$ & $\begin{array}{l}\text { Innovative } \\
\text { scenario }\end{array}$ & Difference & $\begin{array}{l}\text { Difference } \\
\%\end{array}$ \\
\hline ieneral surgery & $24,339.75$ & $24,172.17$ & -167.58 & $-0.69 \%$ \\
\hline b-gyn surgery & & 40,3 & & \\
\hline Orthopedic surgery & $3,610.44$ & $3,590.62$ & -19.82 & $-0.55 \%$ \\
\hline Cardiac surgery & $4,964.85$ & $4,901.48$ & -63.37 & $-1.28 \%$ \\
\hline Other surgery & $7,767.93$ & $7,681.47$ & -86.46 & $-1.11 \%$ \\
\hline Total & $81,049.86$ & $80,657.39$ & -392.47 & $-0.48 \%$ \\
\hline $\begin{array}{l}\text { Maximum } \\
\text { scenario analysis }\end{array}$ & $\begin{array}{l}\text { Baseline } \\
\text { scenario }\end{array}$ & $\begin{array}{l}\text { Innovative } \\
\text { scenario }\end{array}$ & Difference & $\begin{array}{l}\text { Difference } \\
\% \\
\end{array}$ \\
\hline ? & $24,841.86$ & $24,272.59$ & -569.27 & $-2.29 \%$ \\
\hline Ob-gyn surgery & $4 I, 38 I .86$ & $40,819.13$ & -562.73 & $-1.36 \%$ \\
\hline Orthopedic surgery & $3,778.60$ & $3,630.98$ & -147.62 & $-3.91 \%$ \\
\hline Cardiac surgery & $5,026.11$ & $4,905.77$ & -120.34 & $-2.39 \%$ \\
\hline Other surgery & $7,849.02$ & $7,701.74$ & -147.27 & $-1.88 \%$ \\
\hline Total & $82,877.46$ & $81,330.22$ & $-I, 547.24$ & $-1.87 \%$ \\
\hline
\end{tabular}

Abbreviation: ob-gyn, obstetrical-gynecological. 
Table 6 Additional surgical procedures

\begin{tabular}{llll}
\hline & Average & Minimum & Maximum \\
\hline General surgery & 28 & 12 & 49 \\
Ob-gyn surgery & 47 & 21 & 81 \\
Orthopedic surgery & 4 & 2 & 7 \\
Cardiac surgery & 6 & 3 & 10 \\
Other surgery & 9 & 4 & 15 \\
Total & 95 & 41 & 163 \\
\hline
\end{tabular}

Abbreviation: ob-gyn, obstetrical-gynecological.

The evidence provides clinicians and policy-makers with quantitative information, regarding the alternative strategies to adopt within any surgical department, resulting in a consistent economic forecast, in a general context of limited economic resources.

SSCs have a significant resources burden, in terms of extended length of stay and increased costs of treatment. The management of a patient developing an SSC would require a significantly higher amount of resources with respect to a patient not developing any kind of complication. From a hospital perspective, manpower represents an important health care expenditure item, since nursing time accounts for $33 \%-41 \%$ of the total cost of wound care. ${ }^{34}$

The BIA implemented assuming the hospital perspective, reported that the introduction and the adoption of an innovative portable device for negative pressure therapy may be considered an effective strategy, reducing the number of complications arising and also the costs related to SSC management. Mouës et al reported that NPWT, even if associated with higher material expenses, would significantly lower nursing time engagement, thus impacting on the overall management cost. ${ }^{35}$

Hospitals could guarantee to patients a more effective pathway, saving on average $€ 483,787.92$ with the implementation of the new innovative prevention protocol, thus providing patients with a new service and achieving better performances. This is consistent with Searle and Milne's literature review of the cost analyses of NPWT, ${ }^{36}$ concluding that the implementation of NPWT would represent a cost-saving option if compared with conventional therapies: changing dressings less frequently would reduce both exposure to contaminants and disruption of the wound-healing process.

The introduction of the proposed innovative device into clinical practice would allow hospitals and surgical departments to achieve organizational benefits, not only in economic terms but also in terms of decrease of days spent by a surgical patient in the department of reference. Organizational savings could be reinvested within the same specialties, resulting in the treatment of a wider population and a reduction of waiting lists, the latter being a phenomenon perceived by citizens as a major health care problem. In accordance with this, Trueman pointed out that potential benefits of NPWT therapy include freeing up hospital beds and reduced hospital readmissions and nosocomial infections. ${ }^{37}$ While clinicians and decision-makers might hypothesize that the acquisition of the new device could have a direct and negative impact on the budget, a complete economic evaluation of the process is able to verify a completely different result.

In conclusion, the results of this study emphasize the relevance of the entire clinical pathway evaluation, considering not only the single cost component and the technology in itself, but also other economic factors. The evidence demonstrates a significant benefit, even if not so consistent in general economic terms, but interesting from a resources and organizational point of view. A more effective impact for the patients could thus be achieved, applying versatile investments and disinvestment strategies, useful for treating a wider population and reducing waiting lists.

\section{Acknowledgments}

The authors would like to sincerely thank all the health care professionals working in the "Azienda Ospedaliera Universitaria Seconda Università di Napoli”, Naples, Italy, for their valuable support in data retrieval, leading to the improvement of the quality of results presented in the present study.

\section{Author contributions}

Emanuela Foglia, Davide Croce, and Silvestro Canonico conceived the study. Elisabetta Garagiola, Gianluca Pellino, and Giuseppe Signoriello performed data collection. Lucrezia Ferrario and Elisabetta Garagiola analyzed data. Emanuela Foglia and Lucrezia Ferrario wrote the paper. Davide Croce, Silvestro Canonico, Giuseppe Signoriello, and Gianluca Pellino critically reviewed the paper. All authors contributed toward data analysis, drafting and critically revising the paper and agree to be accountable for all aspects of the work.

\section{Disclosure}

The authors report no conflicts of interest in this work.

\section{References}

1. Stevens DL. Treatments for skin and soft-tissue and surgical site infections due to MDR Gram-positive bacteria. J Infect. 2009;59 Suppl 1:S32-S39.

2. Nichols RL. Preventing surgical site infections: a surgeon's perspective. Emerg Infect Dis. 2001;7(2):220-224.

3. Fiorio M, Marvaso A, Viganò F, Marchetti F. Incidence of surgical site infections in general surgery in Italy. Infection. 2006;34(6):310-314.

4. Emmerson AM, Enstone JE, Griffin M, Kelsey MC, Smyth ET. The Second National Prevalence Survey of infections in hospitals-overview of the results. J Hosp Infect. 1996;32(3):175-190. 
5. Reilly JS, Baird D, Hill R. The importance of definitions and methods in surgical wound infection audit. J Hosp Infect. 2001;47(1):64-66.

6. de Lissovoy G, Fraeman K, Hutchins V, Murphy D, Song D, Vaughn BB. Surgical site infection: incidence and impact on hospital utilization and treatment costs. Am J Infect Control. 2009;37(5):387-397.

7. Blackham AU, Farrah JP, McCoy TP, Schmidt BS, Shen P. Prevention of surgical site infections in high-risk patients with laparotomy incisions using negative-pressure therapy. Am J Surg. 2013;205(6):647-654.

8. Posnett J, Gottrup F, Lundgren H, Saal G. The resource impact of wounds on health-care providers in Europe. J Wound Care. 2009;18(4):154-161.

9. Gottrup F, Apelqvist J. The challenge of using randomized trials in wound healing. Br J Surg. 2010;97(3):303-304.

10. Hedrick TL, Sawyer RG, Friel CM, Stukenborg GJ. A method for estimating the risk of surgical site infection in patients with abdominal colorectal procedures. Dis Colon Rectum. 2013;56(5):627-637.

11. Selvaggi F, Pellino G, Sciaudone G, et al. New advances in negative pressure wound therapy (NPWT) for surgical wounds of patients affected with Crohn's disease. Surg Technol Int. 2014;24:83-89.

12. Pellino G, Sciaudone G, Candilio G, Campitiello F, Selvaggi F, Canonico S. Effects of a new pocket device for negative pressure wound therapy on surgical wounds of patients affected with Crohn's disease: a pilot trial. Surg Innov. 2014;21(2):204-212.

13. World Health Organization. WHO guidelines for safe surgery: 2009: safe surgery saves lives. Available from: http://apps.who.int/iris/bitstr eam/10665/44185/1/9789241598552_eng.pdf. Accessed October 20, 2016.

14. Philbeck TE Jr, Whittington KT, Millsap MH, Briones RB, Wight DG, Schroeder WJ. The clinical and cost effectiveness of externally applied negative pressure wound therapy in the treatment of wounds in home healthcare Medicare patients. Ostomy Wound Manage. 1999;45(11):41-50.

15. Canonico S, Campitiello F, Corte AD, Padovano V, Pellino G. Treatment of leg chronic wounds with dermal substitutes and thin skin grafts. In: Gore M, editor. Skin Grafts. InTech; 2013.

16. Malmsjö M, Borgquist O. NPWT settings and dressing choices made easy. Wounds Int. 2010;1(3):1-6.

17. DeCarbo WT, Hyer CF. Negative-pressure wound therapy applied to high-risk surgical incisions. J Foot Ankle Surg. 2010;49(3): 299-300.

18. Pellino G, Sciaudone G, Candilio G, et al. Complications and functional outcomes of restorative proctocolectomy for ulcerative colitis in the elderly. BMC Surg. 2013;13 Suppl 2:S9.

19. Baharestani MM, Gabriel A. Use of negative pressure wound therapy in the management of infected abdominal wounds containing mesh: an analysis of outcomes. Int Wound J. 2011;8(2):118-125.

20. Stannard JP, Atkins BZ, O'Malley D, et al. Use of negative pressure therapy on closed surgical incisions: a case series. Ostomy Wound Manage. 2009;55(8):58-66.

21. Lillis K. Effective wound care requires look at total patient picture. Healthcare Purch News. 2003;27(1):32.
22. Cipolla J, Baillie DR, Steinberg SM, et al. Negative pressure wound therapy: unusual and innovative applications. Scientist. 2008;2(3):15-29.

23. Fogg E. Best treatment of nonhealing and problematic wounds. JAAPA. 2009;22(8):46-48.

24. Krug E, Berg L, Lee C, et al; International Expert Panel on Negative Pressure Wound Therapy [NPWT-EP]. Evidence-based recommendations for the use of negative pressure wound therapy in traumatic wounds and reconstructive surgery: steps towards and international consensus. Injury. 2011;42 Suppl 1:S1-S12.

25. Adogwa O, Fatemi P, Perez E, et al. Negative pressure wound therapy reduces incidence of postoperative wound infection and dehiscence after long-segment thoracolumbar spinal fusion: a single institutional experience. Spine J. 2014;14(12):2911-2917.

26. Hyldig N, Birke-Sorensen H, Kruse M, et al. Meta-analysis of negative-pressure wound therapy for closed surgical incisions. Br J Surg. 2016;103(5):477-486.

27. Bullough L, Wilkinson D, Burns S, Wan L. Changing wound care protocols to reduce postoperative caesarean section infection and readmission. Wounds UK. 2014;10(1):84-89.

28. Witt-Majchrzak A, Żelazny P, Snarska J. Preliminary outcome of treatment of postoperative primarily closed sternotomy wounds treated using negative pressure wound therapy. Pol Przegl Chir. 2015;86(10):456-465.

29. EUnetHTA. HTA Core Model. Version 3.0. 2016. Available from: http://eunethta.eu/sites/5026.fedimbo.belgium.be/files/HTACoreModel 3.0.pdf. Accessed November 4, 2016.

30. Cooper R, Kaplan RS. Cost and Effect. Boston, MA: Harvard Business School Press; 1998.

31. Drummond MF, Sculpher MJ, Torrance GW, O'Brien BJ, Stoddart GL. Methods for the Economic Evaluation of Health Care Programmes. Oxford: Oxford University Press; 2005.

32. Mauskopf JA, Sullivan SD, Annemans L, et al. Principles of good practice for budget impact analysis: report of the ISPOR task force on good research practices - budget impact analysis. Value Health. 2007;10(5):336-347.

33. Assessorato alla Sanità di Regione Campania. Sorveglianza delle infezioni del sito chirurgico in Campania. [Surveillance of surgical site infections in Campania Region.] 2015. Available from: http://www. regione.campania.it/assets/documents/report-isc-campania-2011-2014. pdf. Accessed October 20, 2016.

34. Drew P, Posnett J, Rusling L; Wound Care Audit Team. The cost of wound care for a local population in England. Int Wound J. 2007;4(2):149-155.

35. Mouës CM, van den Bemd GJ, Meerding WJ, Hovius SE. An economic evaluation of the use of TNP on full-thickness wounds. $J$ Wound Care. 2005;14(5):224-227.

36. Searle R, Milne J. Tools to compare the cost of NPWT with advanced wound care: an aid to clinical decision-making. Wounds $U K$. 2010;6(1):106-109.

37. Trueman P. Cost-effectiveness considerations for home health V.A.C. Therapy in the United States of America and its potential international application. Int Wound J. 2008;5 Supp1 2:23-26.

\section{ClinicoEconomics and Outcomes Research}

\section{Publish your work in this journal}

ClinicoEconomics and Outcomes Research is an international, peerreviewed open-access journal focusing on health technology assessment, pharmacoeconomics and outcomes research in the areas of diagnosis, medical devices, and clinical, surgical and pharmacological intervention. The economic impact of health policy and health systems
Submit your manuscript here: https://www.dovepress.com/clinicoeconomics-and-outcomes-reserch-joust

organization also constitute important areas of coverage. The manuscript management system is completely online and includes a very quick and fair peer-review system, which is all easy to use. Visit http://www.dovepress.com/testimonials.php to read real quotes from published authors. 